\title{
PRIMARY SJÖGREN'S SYNDROME PATIENTS WITH BETTER LEVELS OF PHYSICAL ACTIVITY PRESENT LESS FATIGUE AND BETTER QUALITY OF LIFE
}

Lara Betini Altoé ${ }^{1}$, Nicole Reis Souza da Silva ${ }^{1}$, Jéssica Carvalho da Motta ${ }^{1}$, Ana Paula Truhlar Pedrini ${ }^{1}$, Bianca Domingos Noronha ${ }^{1}$, Pedro Henrique Alves dos Santos ${ }^{1}$, Letícia Fonseca Favarato², Luíza Vallory Alochio², Weider Andrade Tomé2, Érica Vieira Serrano ${ }^{3}$, Ana Paula Espíndula Gianórdoli ${ }^{3}$, Valéria Valim ${ }^{3,4}$, Samira Tatiyama Miyamoto ${ }^{5, *}$

1.Universidade Federal do Espírito Santo, Vitória (ES), Brazil.

*Corresponding author: sa.miyamoto@hotmail.com

\section{BACKGROUND}

Primary Sjogren's syndrome (pSS) is a chronic autoimmune disease that affects several systems, such as musculoskeletal and cardiorespiratory, leading to physical and psychosocial impairment. Patients with pSS, when compared to healthy individuals, have less aerobic and physical capacity, as well as low levels of physical activity. The objective was to assess the level of physical activity in patients with $\mathrm{pSS}$.

\section{MATERIAL AND METHODS}

A cross-sectional observational study was carried out with 45 pSS patients from one tertiary hospital in Vitória/ES belonging to the Brazilian Registry of Sjögren's Syndrome (REBRASS). Demographic and clinical data were collected: gender, age, ethnicity, employment and marital status, body mass index (BMI), time of symptoms and time of diagnosis. Patients were evaluated by International Physical Activity Questionnaire - short form (IPAQ-SF), Sjögren's Syndrome Disease Activity Index (ESSDAI), Sjögren's Syndrome Disease Damage Index (SSDDI), Sjögren's Syndrome Patient Reported Index (EPSSRI), Functional Assessment of Chronic Illness Therapy Fatigue Subscale (FACIT-Fatigue), Short-Form Health Survey (SF-36), EuroQoL (EQ-5D), Hospital Anxiety and Depression Scale (HADS) and Epworth Sleepiness Scale (ESE). Patients were divided into two subgroups according to the IPAQ classification: subgroup 1 - very active/active $(n=25)$ and subgroup 2 - irregularly active/sedentary $(n=20)$. Student's t-test or Mann-Whitney test and chi-squared test were used for statistical analysis. The level of significance considered was $p<0.05$.

\section{RESULTS}

There was no significant difference in demographic and clinical variables between the two subgroups. Statistically significant differences between subgroup 1 and subgroup 2 were: total IPAQ (3077.1 $\pm 2764.1 \times 740.7 \pm 731.4)$, IPAQ walking $(517.4 \pm 523.7 \times 309.7 \pm 444.0)$, moderate IPAQ $(1741.6 \pm 1925.7 \times 351.0 \pm 718.8)$, vigorous IPAQ $(818.1 \pm 1567.6 \times 80.0 \pm 157.9)$, FACIT - fatigue ( $37.1 \pm 9.7 \times 30.3 \pm 11.5)$, SF-36 vitality ( $57.4 \pm 21.6 \times 41.0 \pm 25.8)$; SF-36 social aspects $(70.5 \pm 24.2 \times 51.9 \pm 27.9)$ and SF-36 mental health $(64.8 \pm 21.5 \times 48.4 \pm 28.2)$. In subgroup 1, $12(48 \%)$ patients performed regular physical exercise, while in subgroup 2 , only $4(20 \%)$.

\section{CONCLUSION}

Very active and active patients obtained a better level of physical activity, less fatigue and better quality of life in the domains of vitality, social aspects and mental health when compared to irregularly active and sedentary patients. 